\title{
The abnormal nucleus as a cause of congenital facial palsy
}

\author{
Barbara Jemec, Adriaan O Grobbelaar, Douglas H Harrison
}

\begin{abstract}
Background-Congenital facial palsy (CFP) is clinically defined as facial palsy present at birth. It is associated with considerable disfigurement and causes functional and emotional problems for the affected child. The aetiology of the majority of cases however, remains elusive.

Aims-To investigate the role of a neuroanatomical abnormality as a cause of unilateral CFP.

Methods-Magnetic resonance imaging (MRI) scans were performed on 21 patients with unilateral CFP. Fifteen patients had unilateral CFP only; six suffered from syndromes which can include unilateral CFP.

Results-Of the 15 patients with unilateral CFP only, four (27\%) had an abnormal nucleus or an abnormal weighting of this area on the MRI scan, compared to one $(17 \%)$ of the remaining six patients.

Conclusion-Developmental abnormalities of the facial nucleus itself constitute an important, and previously ignored, cause of monosymptomatic unilateral CFP.

(Arch Dis Child 2000;83:256-258)
\end{abstract}

Keywords: congenital facial palsy; nucleus

Congenital facial palsy (CFP) is clinically defined as facial palsy of the 7th cranial nerve which is present at birth or shortly thereafter. ${ }^{1}$ The most recent estimate of the incidence of CFP derives from the United States where the incidence was found to be 2.1 per 1000 live births. ${ }^{2}$ Suggested causes of facial palsy include perinatal trauma, intrauterine posture, intrapartum compression, and familial and congenital aplasia of the nucleus; the latter being most frequently reported for bilateral cases. ${ }^{3}$

This study was undertaken to evaluate the frequency of congenital aplasia of the nucleus, previously believed to be an extremely rare cause.

Department of Plastic Surgery, Mount Vernon Hospital, Rickmansworth Road, Northwood, Middlesex HA6 2RN, UK B Jemec

A O Grobbelaar

D H Harrison

Correspondence to: Miss Jemec

email:bjemec@

krota.domon.co.uk

Accepted 15 May 2000

Patients and methods

Twenty one consecutive patients with CFP referred to Mount Vernon Hospital for facial reanimation were contacted and, following fully informed consent, underwent cranial magnetic resonance image (MRI) scanning which was chosen for its excellent resolution of soft tissues and lack of ionising radiation. A 2 Tesla magnet taking $5 \mathrm{~mm}$ sequences was employed and no contrast was used.

The 14 female and seven male patients were aged 3-66 years (median 19.1). Fifteen had
CFP as their sole symptom and six had syndromes which can include CFP: Poland's syndrome in one, Goldenhaar's syndrome in one, Moebius syndrome in two, and afflicted other unspecified cranial nerves in two.

\section{Results}

MRI SCANS

Of the 21 scans in total, 13 were entirely normal, leaving eight (38\%) abnormal scans. Five $(24 \%)$ of the abnormal scans showed a lesion in the area of the facial nucleus in the pons: in two there was complete absence of the nucleus (fig 1); and in the other three there was an abnormal T1/T2 weighting in the area (fig $2)$. Three (14\%) showed other abnormalities: a prominent circle of Willis, partial agenesis of the corpus callosum, and a cerebellar hypoplasia.

SYNDROMIC PATIENTS

Of the six patients with associated syndromes, four $(66 \%)$ had scans which were entirely normal. One patient $(17 \%)$ suffering from Moebius syndrome had cerebellar hypoplasia and one $(17 \%)$ with Poland's syndrome had an abnormal weighting of the nuclear area.

MONOSYMPTOMATIC CFP

Of the 15 patients with CFP alone, nine had entirely normal scans. Of the abnormal scans,

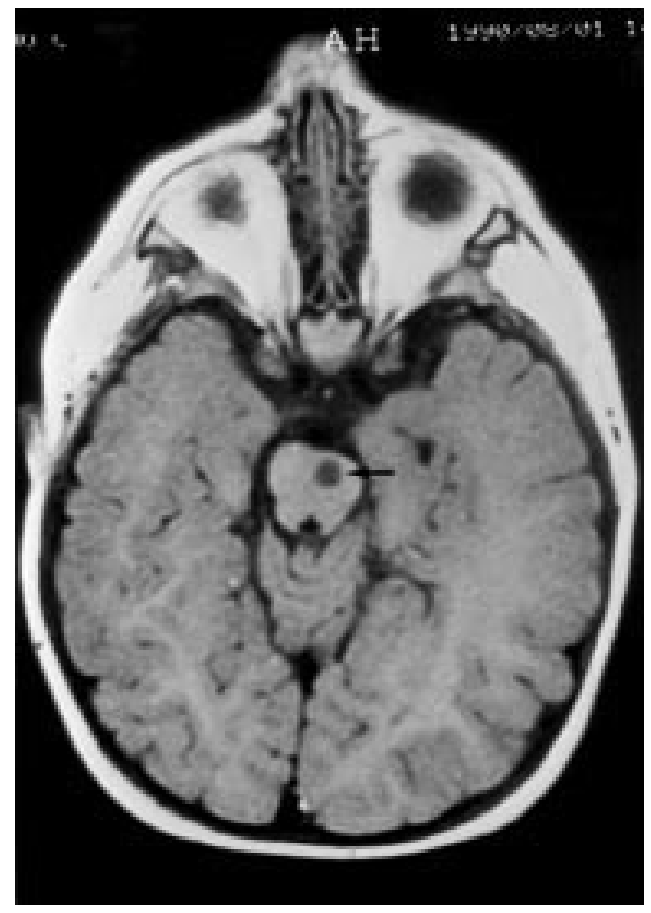

Figure 1 Transverse section cranial MRI scan showing absence of facial nucleus in the pons (arrow). 


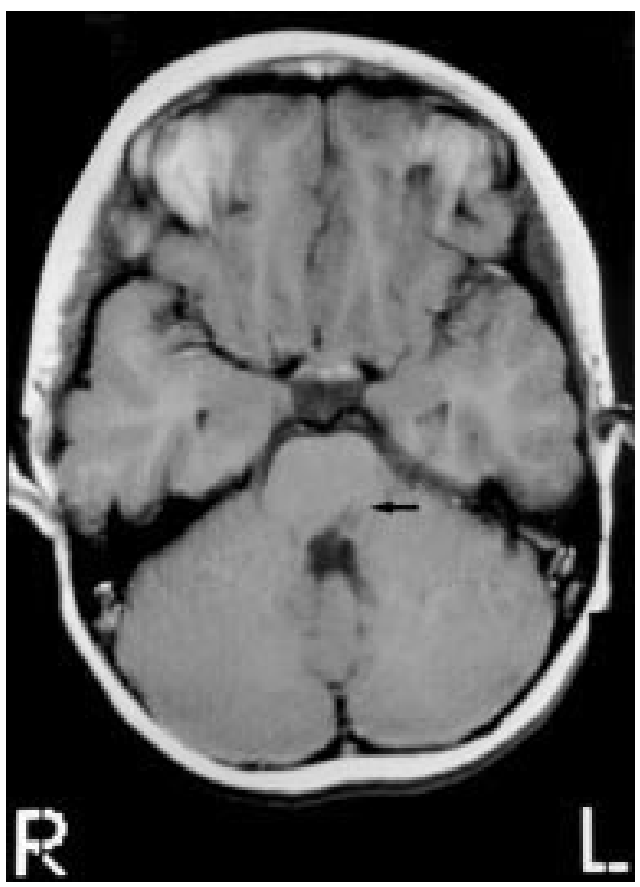

Figure 2 Transverse section cranial MRI scan with arrow showing abnormal T1/T2 weighting of the facial nucleus.

four $(27 \%)$ had an abnormality of the nuclear area and two $(13 \%)$ had either a prominent circle of Willis or a partial agenesis of the corpus callosum. Of the five with an abnormality in the nuclear area, two had a complete absence of the facial nucleus (fig 1), while three had an abnormal T1/T2 weighting (fig 2), indicating gliosis or cyst formation in this area.

\section{Discussion}

The causes of CFP are known to be varied, but the focus so far has been on perinatal factors. Many parents and health care professionals still consider the palsy to be caused by perinatal trauma. There are ample opportunities for the extracranial facial nerve to be damaged during birth owing to its relatively superficial course; several mechanisms have been suggested, apart from instrumentation in assisted delivery. ${ }^{4}$ These include: intrauterine posture, where pressure from the shoulder produces a notable displacement of the jaw and the periaural portions of the head, resulting in sufficient pressure on the peripheral portion of the facial nerve to cause facial weakness ${ }^{6}$; and intrapartum compression, where the foetal head is compressed against a maternal bony prominence such as the pubic rami, the ischial spines, or the sacral prominence, ${ }^{7}$ again damaging the peripheral facial nerve.

A study investigating the association between recognised factors for birth injuries such as maternal primiparity, high birth weight, and the use of obstetric forceps at delivery with CFP, found no connection. ${ }^{8}$ Facial nerve neuropraxia in the newborn, following assisted delivery, usually results in a temporary facial palsy and rarely in permanent disability. Infants with traumatic facial paralysis in contrast to newborns with congenital disorders of facial palsy have a poor prognosis for improvement in facial nerve function. ${ }^{9}$
There are a number of syndromes which encompass congenital facial palsy as part of their symptoms, including the cardiofacial, ${ }^{9}$ Moebius, ${ }^{9}$ Poland's, ${ }^{10}$ and Goldenhaar's ${ }^{11}$ syndrome. The former comprises facial asymmetry when crying, but not at rest. This is attributed to an isolated weakness of the depressor anguli oris and quadratus labii inferiores muscles; the syndrome has been linked to congenital heart defects. ${ }^{9}$ Moebius syndrome is a bilateral facial and abducens nerve palsy. Necropsy studies in Moebius patients have shown defects ranging from hypoplasia to agenesis of the respective cranial nuclei. ${ }^{9}$ Because of the proximity of the nuclei of the 6th and 7 th cranial nerves in the pons, it has not been thought that a neuroanatomical abnormality could be restricted to only one. ${ }^{12}$ Poland's syndrome ${ }^{10}$ consists of unilateral absence of the pectoralis muscles, upper limb defects, and occasionally unilateral CFP. Goldenhaar's syndrome patients $^{11}$ have unilateral facial hypoplasia, occasionally associated with facial palsy, cervical vertebral defects, epibulbar dermoid, and preauricular skintags.

Abnormalities in the peripheral nerve are often associated with abnormalities of the external ear ${ }^{4}$ and occasionally with malformations of the mastoid region. Cases of CFP have been attributed to an agenesis of the petrous portion of the temporal bone, with resulting agenesis of the facial and auditory nerves, the external ear, and the mastoid region. ${ }^{13}$ It has however been pointed out, that the bone and cartilage formation of the mastoid occur after the development of the facial nerve and would therefore appear unable to influence the nerve itself. ${ }^{14}$

In our experience, a thin nerve like structure can be identified on the affected side, but it is still not functional, so the cause seems to lie further centrally.

Permanent CFP can not only be caused by peripheral damage to the facial nerve or syndromes, but also by CNS abnormalities. Permanent CFP also occurs both in isolation or as part of a recognised syndrome.

This study was undertaken to review the frequency of congenital nuclear aplasia, considered a very rare cause of $\mathrm{CFP}^{1}$ until now. Using MRI scans we found that an underlying CNS abnormality was evident in four of $15(27 \%)$ patients with CFP as their sole symptom. This indicates a central cause being far more common than assumed since 1901 when Marfan and Armand-Delille ${ }^{15}$ carried out a postmortem examination on a 3 month old girl with unilateral facial palsy, born at eight months gestation, after an uncomplicated pregnancy, in normal labour, and with a rudimentary external ear, a cul-de-sac external auditory canal, no tympanum, and an aplastic mastoid. ${ }^{7}$ The authors found the root and the nucleus of the facial nerve involved and called this secondary atrophy, but Bonar and Owens in 1929 attributed the findings to primary agenesis of the nucleus with secondary malformations of the ear. ${ }^{1}$

The cause of CFP is still elusive. Several aetiological factors have been identified. It is 
most likely that a combination of central and peripheral factors are involved in most cases. This is against a central degeneration, as a result of the peripheral damage first postulated by Marfan and Armand-Delille in 1901. This would therefore indicate the lack of a nucleus being the primary cause of the CFP and not a result of it.

In a qualitative and quantitative study exploring the distal end of the sural nerve graft, ${ }^{16}$ it was shown that the lack of distal connection did not appear to lead to secondary degeneration of the regenerating myelinated fibres.

CONCLUSION

MRI of the brain of CFP patients has never been attempted to our knowledge. This study suggests that CFP has a central cause in a significant percentage of patients. This is important medicolegally, as all cases are clearly not a result of perinatal trauma.

We wish to thank the Restoration of Appearance of Function Trust for financial support, Professor Baddeley, Dr Wong, and the radiographers at the Paul Strickland Scanner Centre at Mount Vernon Hospital for their cooperation and expertise, and all the patients who with such enthusiasm have participated in our research.

1 Bonar BE, Owens RW. Bilateral congenital facial paralysis. Am f Dis Child 1929;38:1256-72.

2 Falcon A, Ericson E. Facial nerve palsy in the newborn incidence and outcome. Plast Reconstr Surg 1990;85:1-4.
3 Moebius PJ. Ueber Infantilen Kerschwund. Munch Med Wochenschr 1892;39:17-21,41-3,55-8.

4 Smith JD, Crumley RL, Harker A. Facial paralysis in the newborn. Arch Otolaryngol Head Neck Surg 1981;89:10214.

5 May M. Facial paralysis: differential diagnosis and indications for surgical therapy. Clin Plast Surg 1979;6:275-91.

6 Parmalee AH. Molding due to intra-uterine posture: facial paralysis probably due to such molding. Am $\mathcal{f}$ Dis Child 1931;42:1155-9.

7 Knapp L. Fall von Facialisparese bei einem Neugeborenen nach spontaner Geburt. Zentralblatt für Gynäkologie 1896; 20:705-8.

8 Laing JHE, Harrison DH, Jones BM, et al. Is permanent congenital facial palsy caused by birth trauma? Arch Dis Child 1996;74:56-8.

9 Sweeney PJ, Hanson MR. The cranial neuropathies. In: Bradley WG, Daroff RB, Fenichel GM, Marsden CD, eds. Neurology in clinical practice, Vol. II. Oxford: ButterworthHeineman, 1991:1556-7.

10 Mace JW, Kaplan JM, Schanberger JE, et al. Poland's syndrome. Report of seven cases and review of the literature. Clin Pediatr (Phila) 1972;11:98-102.

11 Baraitser M, Winther RM. Genetics and congenital malformations. In: Roberton NRC, ed. Textbook of neonatology, 2nd edition. Edinburgh: Chuchill Livingstone, 1992: 2nd edition.

12 Chadwick D. The cranial nerves and special senses. In: Walton J, ed. Brain's diseases of the nervous system, 10 th edition. Oxford: Oxford University Press, 1993:147.

13 Heller. Contribution a l'étude des paralysies faciales congénitales par agenése du rocher. Thesè de Paris 1903 in Bonar BE, Owens RW. Bilateral congenital facial paralysis. Am $\mathcal{F}$ Dis Child 1929;38:1256-72.

14 Essen-Möller E. Ueber angeborene Radiusdefekte, Ohrdefekte und Facialislähmungen anlässlich eines Falles von multiplen Missbildungen. Zeitschrift für der gestationelle Anultiplen Missbildungen.

15 Marfan A-B, Armand-Delille. Paralysie Faciale Congénitale du Côté Droit. Société médiciale des hôpitaux 1901;18:100714.

16 Jacobs JM, Laing JHE, Harrison DH. Regeneration through a long nerve graft used in the correction of facial palsy. A qualitative and quantitative study. Brain 1996;199:271-9. 